\title{
A catheter malpositioned patient with pain and paresthesia
}

\author{
Akbar Fadaei Haghi ${ }^{1}$, Rouya Shokri ${ }^{1}$, Samad Shams Vahdati ${ }^{1}$, Mina Darei ${ }^{2}$, Farid Eftekhar Milani ${ }^{{ }^{*}}$, \\ Shahrad Tajoddini ${ }^{3}$
}

'Road Traffic Injury Research Center, Emergency Department, Tabriz University of Medical Sciences, Tabriz, Iran

${ }^{2}$ Emergency Department, Tabriz University of Medical Sciences, Tabriz, Iran

${ }^{3}$ Kerman Neuroscience Research Center, Kerman University of Medical Sciences, Kerman, Iran

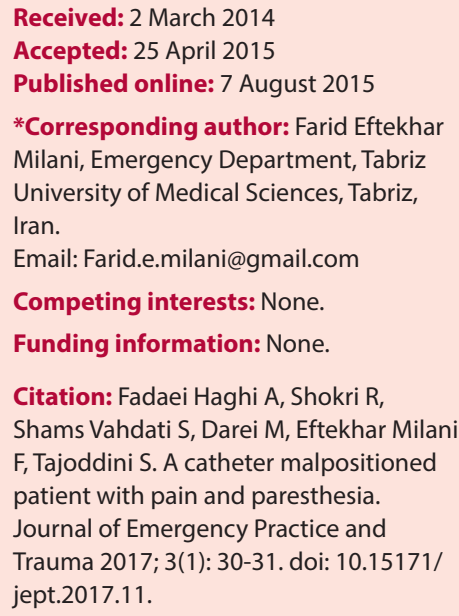

\begin{abstract}
We report a 54-year-old woman with the history of end-stage renal disease (ESRD) who was admitted to our hospital because of volume overload. Due to long-term use of peripheral veins and arteriovenous fistula (AVF) failure, central venous catheterization was the only choice for hemodialysis. She developed right upper extremiti's pain and paresis during hemodialysis. A posteroanterior chest $\mathrm{x}$-ray showed the catheter tip was accidently pushed from right internal jugular vein into right subclavian vein during hemodialysis by the dialysis center nurse. Therefore, we believe that the physician should be aware of any changes in the catheter size after insertion. And a chest $x$-ray should ensure the catheter's correct position in any patient who develops complications.
\end{abstract}

Keywords: Central venous catheterization, Malposition, Subclavian vein

\section{Introduction}

Central venous catheterization has become very common and it is a relatively inexpensive and easy method which can be used for several therapeutic and diagnostic purposes like measuring central venous pressure, fluid and blood transfusion, drug administration, hemodialysis and total parenteral nutrition (TPN). It is associated with many potential complications like other invasive procedures. Malposition as a complication is not a rare occurrence which usually occurs by misdirection of the catheter tip into the major tributaries of the superior vena cava (1). Chest $\mathrm{x}$-ray has an important role in the detection of central venous catheter malposition (2) and it should be done to confirm the position of the catheter tip. In this case report we present a hemodialysis patient in which the catheter tip was malpositioned in the right subclavian vein.

\section{Case report}

A 54-year-old female patient $(65 \mathrm{~kg}, 169 \mathrm{~cm})$ who had undergone hemodialysis several times, came to us because of the failure of an arteriovenous fistula (AVF) which was prepared 1 month before admission. The patient had been treated for end-stage renal disease (ESRD) due to polycystic kidney disease (PKD) and kidney stones. She was volume overloaded and because of longstanding use of peripheral veins for hemodialysis, we have to establish central venous catheter. A temporary double lumen catheter was inserted via the right internal jugular vein. Blood could be easily aspirated and a chest x-ray confirmed the catheter's correct position. The patient was transferred to the dialysis center. We found that the patient was complaining of right upper extremity's pain and paresis during the hemodialysis. A posteroanterior chest $\mathrm{x}$-ray was obtained in which the catheter tip was seen in the ipsilateral subclavian vein (Figure 1). It was revealed that the catheter was manipulated by the nurse during dialysis which caused the catheter coursing from right internal jugular vein into the right subclavian vein. The catheter was removed and correctly positioned via the left internal jugular vein. The pain and paresis of the right upper extremity disappeared. A posteroanterior chest x-ray was preformed and demonstrated that the catheter tip was in the left internal jugular vein.

\section{Discussion}

Nowadays, central venous catheters are commonly used for the determination of central venous pressure, hemodialysis, administration of fluids and blood, and for the TPN. Central venous catheterization is associated with several potential complications including pneumothorax, 


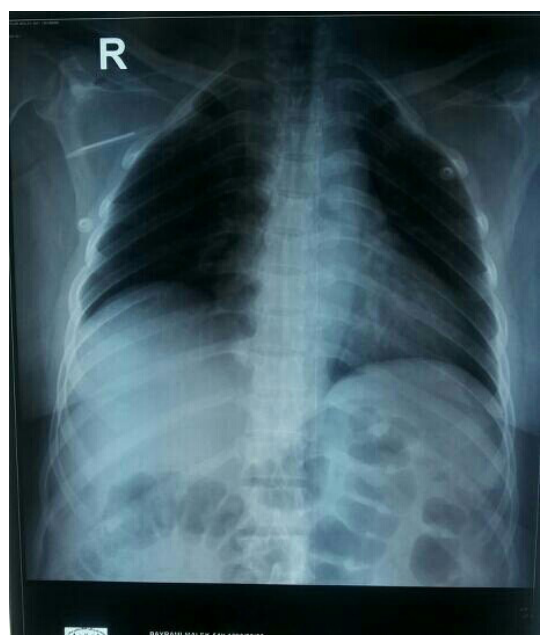

Figure 1. Postero anterior chest $x$-ray showing catheter's tip in subclavian vein.

thrombosis, bleeding, arrhythmias, infection and malposition (3-8). Malposition of central venous catheter is not uncommon and can lead to disastrous consequences like perforation, thrombosis, local toxicity, neurologic deficit and hematoma $(9,10)$. Therefore, a chest X-ray should be obtained after insertion of the catheter to ensure its position (6) and also any minimal changes in the size of catheter which is inserted should be evaluated by the physician. A common malposition occurs when the catheter entering the internal jugular vein, descends the ipsilateral subclavian vein (2). Subclavian vein continues the axillary as the main venous stem of the upper limb, follows the subclavian artery, and joins with the internal jugular vein to form the brachiocephalic vein. In some situations congenital and acquired variations can cause central venous catheter malposition. Some of the anatomical variations in neck veins such as persistent superior vena cava, left superior vena cava or dextrocardia are too rare (9). Since our patient had the history of multiple previous peripheral venous catheterization and AVF placement, some acquired complications like thrombosis is very possible.

\section{Conclusion}

This case shows that, dislocation and malposition of catheter is not a rare complication. Therefore, any related complaints should be heeded by physicians accurately and chest $\mathrm{x}$-ray is one of the best modalities for this reason.
Ethical issues

Written informed consent was obtained from the patient.

\section{Authors' contributions}

AFH: case finding; RS, case management; SSV; case presentation; MD: writing; FEM and ST; critical assesment.

\section{References}

1. Webb JG, Simmonds SD, Chan-Yan C. Central venous catheter malposition presenting as chest pain. Chest 1986; 89(2): 309-12.

2. Bankier AA, Mallek R, Wiesmayr MN, Fleischmann D, Kranz A, Kontrus M, et al. Azygos arch cannulation by central venous catheters: radiographic detection of malposition and subsequent complications. J Thorac Imaging 1997; 12(1): 64-9.

3. Moeinipour AA, Amouzeshi A, Joudi M, Fathi M, Jahanbakhsh S, Hafez S, et al. A rare central venous catheter malposition: a case report. Anesth Pain Med 2014; 4(1): e16049.

4. Muhm M, Sunder-Plassmann G, Druml W. Malposition of a dialysis catheter in the accessory hemiazygos vein. Anesth Analg 1996; 83(4): 883-5.

5. Mohan PR, Hegde H, Padmanabha S, Qureshi FM, Imran S. Malposition of central venous catheter - three case reports. IOSR Journal of Dental and Medical Sciences 2013; 11(6): 7-9.

6. Ikeda S, Sera Y, Yamamoto H, Terakura H, Yoshida M, Uchino S, et al. Malposition of a totally implantable venous access catheter in the azygous vein: report of a case. Surg Today 1995; 25(7): 649-50.

7. Cassidy FP Jr, Zajko AB, Bron KM, Reilly JJ Jr, Peitzman AB, Steed DL. Noninfectious complications of long-term central venous catheters: radiologic evaluation and management. AJR Am J Roentgenol 1987; 149(4): 671-5.

8. Maffessanti M, Bortolotto P, Kette F, Bellis GB. Radiological detection of malpositions and complications of central venous catheters. Eur J Radiol 1989; 9(2): 101-4.

9. Chantler J. Applied anatomy of the central veins. In: Hamilton H, Bodenham AR. Central Venous Catheters. Oxford, UK: Wiley-Blackwell; 2009.

10. Kusminsky RE. Complications of central venous catheterization. J Am Coll Surg 2007; 204(4): 681-96. 